\title{
Synthesis, characterization, and controlled nitric oxide release from $S$-nitrosothiol-derivatized fumed silica polymer filler particles
}

\author{
Megan C. Frost ${ }^{1}$, Mark E. Meyerhoff ${ }^{1}$ \\ ${ }^{1}$ Department of Chemistry, University of Michigan, 930 N. University, Ann Arbor, Michigan 48109-1055
}

Received 24 September 2004; accepted 2 November 2004

Published online 28 January 2005 in Wiley InterScience (www.interscience.wiley.com). DOI: 10.1002/jbm.a.30275

\begin{abstract}
A new type of nitric oxide (NO)-releasing material is described that utilizes $S$-nitrosothiols anchored to tiny fumed silica (FS) particles as the NO donor system. The synthetic procedures suitable for tethering three different thiol species (cysteine, $\mathrm{N}$-acetylcysteine, and $\mathrm{N}$-acetylpenicillamine) to the surface of FS polymer filler particles are detailed. The thiol-derivatized particles are converted to their corresponding $S$-nitrosothiols by reaction with $t$-butylnitrite. The total NO loading on the resulting particles range from $21-138 \mathrm{nmol} / \mathrm{mg}$ for the three different thiolderivatized materials [S-nitrosocysteine-(NO-Cys)-FS, S-nitroso- $\mathrm{N}$-acetylcysteine (SNAC)-FS, and $S$-nitroso- $N$ acetylpenicillamine (SNAP)-FS], with SNAP-FS yielding the highest NO loading. NO can be generated from these particles when suspended in solution via the addition of copper(II) ions, ascorbate, or irradiation with visible light. The SNAC-FS and SNAP-FS particles can be blended in polyurethane and silicone rubber matrixes to create films that re-
\end{abstract}

lease NO at controlled rates. Polyurethane films containing SNAC-FS submerged in phosphate-buffered saline ( $\mathrm{pH} 7.4)$ generate NO surface fluxes $\sim 0.1-0.7 \times 10^{-10} \mathrm{~mol} \mathrm{~cm}{ }^{-2}$ $\min ^{-1}$ and SNAP-FS films generate NO fluxes of $\sim 0-7.5 \times$ $10^{-10} \mathrm{~mol} \mathrm{~cm}^{-2} \mathrm{~min}^{-1}$ upon addition of increasing amounts of copper ions. Silicone rubber films containing SNAC-FS or SNAP-FS do not liberate NO upon exposure to copper ions or ascorbate in phosphate-buffered saline solution. However, such films are shown to release NO at rates proportional to increasing intensities of visible light impinging on the films. Such photoinitiated NO release from these composite materials offers the first NO-releasing hydrophobic polymers with an external on/off trigger to control $\mathrm{NO}$ generation. (C) 2005 Wiley Periodicals, Inc. J Biomed Mater Res 72A: 409-419, 2005

Key words: nitric oxide; S-nitrosothiols; hydrophobic polymers; photoinitiated release; polymer fillers

\section{INTRODUCTION}

Polymeric materials are used to fabricate or coat a wide variety of biomedical devices, including intravascular sensors, extracorporeal circuit tubings, catheters, cannula, and vascular grafts. ${ }^{1-3}$ Regardless of the specific polymer used to construct such devices, all materials currently used inspire a biological response upon exposure to blood and tissue. For example, the surfaces of blood-contacting devices cause platelet adhesion and activation, triggering the coagulation cas-

Correspondence to: M. E. Meyerhoff; e-mail: mmeyerho@ umich.edu

Contract grant sponsor: National Institutes of Health; contract grant number: NIH EB00783

Contract grant sponsor: NIH Cellular Biotechnology Training Program at the University of Michigan; contract grant number: T32 GM08353

Contract grant sponsor: Division of Analytical Chemistry, 2003 ACS Summer Fellowship

(c) 2005 Wiley Periodicals, Inc. cade that results in thrombus formation on the surface. This clot formation can interfere with the functioning of the device (e.g., intravascular sensors no longer measure analyte in bulk blood, vascular grafts become occluded, etc.) and pose serious health risks to patients. Nitric oxide (NO) has been shown to possess a wide variety of physiological functions and is naturally produced by a number of cells. NO is a potent inhibitor of platelet activation and adhesion. ${ }^{4,5} \mathrm{NO}$ has also been shown to inhibit smooth muscle cell proliferation associated with restenosis ${ }^{6}$ and neointimal hyperplasia, ${ }^{7}$ inhibit bacterial cell adhesion, ${ }^{8}$ and to be involved in macrophage function via cytotoxic effects. ${ }^{9}$ The potential exists for many biomedical devices fabricated from polymers that possess NO-release capability to exhibit enhanced biocompatibility and therefore improved performance.

To date, a variety of NO-release materials have been synthesized in our laboratory and elsewhere that incorporate NO donors into polymer matrixes by blending discrete species into the polymer ${ }^{10-15}$ or covalently linking the donor to a polymer backbone. ${ }^{15-18}$ The 
kinetics of NO release from these materials can be modulated by changing the polymer matrix or structure of the NO donor. Another strategy for making NO-releasing polymers is to derivatize polymer fillers [e.g., fumed silica (FS) or titanium dioxide particles] with NO donors. ${ }^{18}$ Derivatized fillers have the advantage of imparting NO generation to a wide variety of polymers simply by blending the filler into the polymer (i.e., the fundamental polymer chemistry is not altered by adding the NO donor) and modulating the NO flux from the cured polymer by changing the amount of filler embedded. Additionally, the risk of leaching byproducts resulting from NO release is eliminated because the NO donor is covalently linked to the filler particles that are mechanically entrapped in the cured polymer matrix. This concept was first demonstrated by Zhang et al. ${ }^{18}$ who showed that alkylamine groups could be covalently linked to FS particles and subsequently diazeniumdiolated upon reaction with $\mathrm{NO}$ in the presence of a methoxide base. The resulting particles were blended into polyurethane (PU) and coated on the inner surface of poly(vinyl chloride) tubing used in extracorporeal circuitry. Initial in vivo experiments with these materials demonstrated that the NO-generating polymers coated on the inner walls of extracorporeal circuitry ${ }^{18}$ reduced thrombus formation and decreased platelet consumption. These promising results and the myriad of potential applications of $\mathrm{NO}$-generating materials to the fabrication of medical devices warrants further development of new NO-releasing materials, especially ones in which the NO-release properties can be controlled more precisely.

$S$-Nitrosothiols (RSNOs) are a class of NO donor that may be useful in developing NO-releasing polymers. RSNOs are thought to serve as a reservoir and transporter of NO within biological systems. ${ }^{19} \mathrm{~S}-\mathrm{Ni}$ troso-serum albumin and $S$-nitrosoglutathione are the two most abundant naturally occurring RSNOs present in circulating blood, and S-nitrosoglutathione is also found within cells. ${ }^{20}$ The stability of RSNOs is determined by the $\alpha$ and $\beta$ substitution with respect to the sulfur atom. ${ }^{21}$ Primary and secondary RSNOs, such as $\mathrm{S}$-nitrosocysteine (NO-Cys) and S-nitroso- $\mathrm{N}$ acetyl-L-cysteine (SNAC), are unstable, whereas tertiary RSNOs, such as $\mathrm{S}$-nitroso- $\mathrm{N}$-acetylpenicillamine (SNAP), are quite stable. ${ }^{21}$

The S-NO bond of RSNOs can be cleaved to release NO by three known mechanisms. ${ }^{21}$ Copper ionmediated decomposition requires $\mathrm{Cu}^{+2}$ to be reduced to $\mathrm{Cu}^{+1}$. Copper(I) then reacts with the RSNO to release $\mathrm{NO}$, forming a thiolate anion and regenerating $\mathrm{Cu}^{+2}{ }^{22}$ The thiolate can further reduce the $\mathrm{Cu}^{2+}$ back to $\mathrm{Cu}^{+}$creating a catalytic cycle to degrade all the RSNO species present. In addition, ascorbate is also a sufficient reducing agent to generate $\mathrm{Cu}^{+1}$ from $\mathrm{Cu}^{2+}$ under physiological conditions. A second reported decomposition pathway of RSNOs is their direct reaction with ascorbate, at concentrations greater than millimolar level, to release NO and produce a free thiol and dehydroascorbate. ${ }^{23}$ The third mechanism of decomposition is homolytic cleavage of the $\mathrm{S}-\mathrm{NO}$ bond by light, at either $330-350$ or $550-600 \mathrm{~nm}$, releasing $\mathrm{NO}$ and producing disulfide bonds from the radicals of the parent thiols that are formed during the photolytic reaction. ${ }^{24}$

Several reports have previously utilized light to generate NO by decomposing RSNOs that are either endogenously present in biological systems ${ }^{25}$ or have been incorporated into monolayers or hydrogels. ${ }^{14,26,27}$ Etchenique et al. ${ }^{26}$ used photolytic release of $\mathrm{NO}$ from monolayers of nitrosated dithiothreitol attached to gold surfaces. Although this work suggests the possibility of photoinitiated temporal and spatial control of NO release, it has limited applications because there is a very small reservoir of $\mathrm{NO}$ actually available in the monolayer. Shishido et al. ${ }^{27}$ blended $S$-nitrosoglutathione or S-nitroso- $\mathrm{N}$-acetylcysteine into hydrogels that release $\mathrm{NO}$ at body temperature and demonstrated enhanced NO release when the materials were simultaneously irradiated with light. This material, however, continuously released NO upon initiation of the thermal decomposition pathway as well as having the potential to leach the NO donor from the hydrogel matrix.

Recently, we reported preliminary data for the photoinitiated release of NO from silicone rubber films embedded with SNAP attached to tiny FS particles. ${ }^{28}$ Herein, we describe in detail the synthetic methods used to covalently link several RSNOs (NO-Cys, SNAC, and SNAP) to 7- to 10-nm-diameter FS particles. The characterization of the resultant particles and their NO-release properties in response to copper ions, ascorbate, and light are reported. SNAC-FS and SNAP-FS particles were further blended into the center layer of trilayer silicone rubber (SR) or PU films. The NO-release properties of these composite films are characterized in detail with respect to the response upon addition of copper and ascorbate ions to the solution bathing the films. Photoinitiated NO release is also examined for these polymeric materials. The photoinitiated NO generation from these RSNO-FSdoped materials represents the first hydrophobic polymer systems that have a controllable, external on/off trigger for the local generation of NO.

\section{EXPERIMENTAL}

\section{Materials}

$\mathrm{N}$-Acetyl-L-cysteine, triphenylmethanol, sodium acetate, acetic acid, $\mathrm{N}$-acetyl-DL-penicillamine, magnesium 
sulfate, FS (7- to 10-nm diameter), $S$-trityl- $N$-Boccycteine, $O$-(benzotriazol-1-yl)- $N, N, N^{\prime}, N^{\prime}$-tetramethyluronium hexafluorophosphate (HBTU), glycine hydrochloride, cysteine hydrochloride, 5,5'-dithio-bis(2nitrobenzoic acid) (Ellman's reagent), and sodium ascorbate were purchased from Sigma (St. Louis, MO). Boron trifluoride diethyletherate $\left(\mathrm{BF}_{3}\right.$-etherate), diethyl ether, acetic anhydride, pyridine, dimethylformamide (DMF), diisopropylethylamine (DIEA), trifluoroacetic acid (TFA), and methanol were obtained from Aldrich (Milwaukee, WI). Chloroform $\left(\mathrm{CHCl}_{3}\right)$, hydrochloric acid $(\mathrm{HCl})$, hexanes, toluene, dichloromethane $\left(\mathrm{CH}_{2} \mathrm{Cl}_{2}\right)$, tetrahydrofuran (THF), and sodium phosphate (monobasic) were purchased from Fisher Scientific (Pittsburgh, PA). 1,4,8,11-Tetraazacyclotetradecane (cyclam) and $t$ butylnitrite were products of Acros (Pittsburgh, PA). (3-Aminopropyl)trimethoxysilane and 2-nitrophenyl octylether (NPOE) were purchased from Fluka (Milwaukee, WI). 3-(2-Furoyl)quinoline-carbaldehyde (FQCA) was obtained from Molecular Probes (Eugene, OR). Philips Director Bulbs (40, 60, 75, and $100 \mathrm{~W})$ were purchased from Meijer, Inc. (Ann Arbor, MI). Chelex 100 Resin was a product of Bio-Rad Laboratories (Hercules, CA). TecoFlex ${ }^{\circledR}$ SG-80A PU was a gift from Thermedics, Inc. (Woburn, MA). Dow Corning RTV 3140 Silicone Rubber (SR) was purchased from World Precision Instruments (Sarasota, FL). All chemicals were used as received except the $t$-butylnitrite (see below).

\section{Preparation of S-trityl- $\mathrm{N}$-acetyl-L-cysteine}

The method of Zee-Cheng and Cheng ${ }^{29}$ was adapted to prepare $S$-trityl-N-acetyl-L-cysteine. Thirty millimole $\mathrm{N}$-acetyl-L-cysteine was dissolved in $25 \mathrm{~mL}$ of acetic acid. Thirty-five millimole thiphenylmethanol and $6.5 \mathrm{~mL}$ of $\mathrm{BF}_{3}$-etherate were then added with stirring. The reaction proceeded at $25^{\circ} \mathrm{C}$ for $2 \mathrm{~h}$. Eighty milliliters of a saturated sodium acetate solution and $160 \mathrm{~mL}$ of $\mathrm{H}_{2} \mathrm{O}$ were then added. The mixture was ice cooled and a white solid collected. The crude product was stirred with $150 \mathrm{~mL}$ of $\mathrm{H}_{2} \mathrm{O}$ and $120 \mathrm{~mL}$ of diethylether for $4 \mathrm{~h}$ at room temperature. The white solid was collected and washed several times with $\mathrm{H}_{2} \mathrm{O}$. Purity of the $S$-trityl- $\mathrm{N}$-acetyl-L-cysteine was confirmed with ${ }^{1} \mathrm{H}$ NMR (data not shown).

\section{Preparation of $\mathrm{N}$-acetyl-DL-penicillamine thiolactone}

To form this thiolactone, $4.9 \mathrm{~g}$ of $N$-acetyl-DL-penicillamine was dissolved in $\sim 10 \mathrm{~mL}$ of pyridine and ice cooled with stirring for $30 \mathrm{~min}$. A solution of $\sim 10$ $\mathrm{mL}$ of acetic anhydride and $\sim 10 \mathrm{~mL}$ of pyridine was also stirred and cooled for $30 \mathrm{~min}$. The two solutions

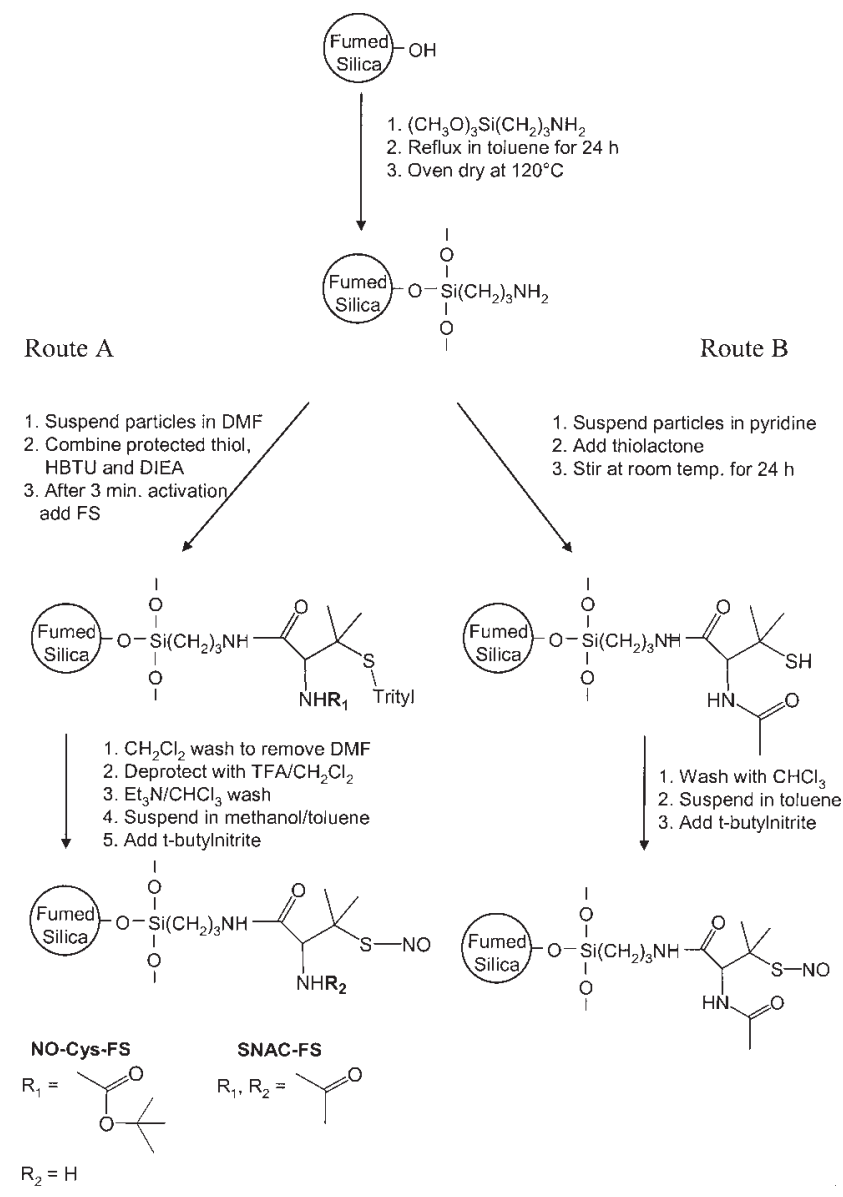

Figure 1. Schemes used to derivatize FS with three different RSNOs. Route A leads to the synthesis of NO-Cys-FS and SNAC-FS; route B illustrates the method used to obtain SNAP-FS.

were then combined and stirred at room temperature for $24 \mathrm{~h}$. The solvent was removed with a roto-vap at $60^{\circ} \mathrm{C}$. The resulting amber oil was redissolved in $\mathrm{CHCl}_{3}$, washed three times with $1 \mathrm{~N} \mathrm{HCl}(\mathrm{aq})$, and dried with magnesium sulfate. The $\mathrm{CHCl}_{3}$ was then removed with the roto-vap. The crystals were collected with hexanes and suction filtration. Purity of the thiolactone was confirmed via ${ }^{1} \mathrm{H}$ NMR (data not shown).

\section{Derivatization of FS particles}

Figure 1 illustrates the overall procedure developed to tether the thiol containing amino acids to the surface of the polymer filler particles. Aminopropyl FS was first prepared by refluxing $5.3 \mathrm{~g}$ of FS with $4.9 \mathrm{~g}$ of (3-aminopropyl)trimethoxysilane in $500 \mathrm{~mL}$ of toluene for $24 \mathrm{~h}$. The derivatized FS was then washed three times with fresh toluene and oven dried at $120^{\circ} \mathrm{C}$ overnight.

To attach cysteine or N-acetylcysteine to the FS par- 
ticles, $2.3 \mathrm{~g}$ of HBTU was dissolved in $15 \mathrm{~mL}$ of DMF. This solution was added to $2.76 \mathrm{~g}$ of $S$-trityl-N-Boc-Lcysteine or $2.55 \mathrm{~g}$ of $S$-trityl- $\mathrm{N}$-acetyl-L-cysteine. An aliquot of $1.38 \mathrm{~mL}$ of DIEA was then added and the solution was allowed to react for $\sim 5 \mathrm{~min}$. This activated amino acid solution was subsequently combined with $1 \mathrm{~g}$ of aminopropyl FS and stirred for 40 min. The particles were washed three times with $\mathrm{CHCl}_{3}$ and vacuum dried. The protecting groups were then removed by stirring in a $10 \%$ TFA $/ 90 \% \mathrm{CH}_{2} \mathrm{Cl}_{2}$ $(\mathrm{v} / \mathrm{v})$ solution for $45 \mathrm{~min}$. The final deprotected particles were washed three times with fresh $\mathrm{CH}_{2} \mathrm{Cl}_{2}$ and vacuum dried.

$\mathrm{N}$-Acetyl-DL-penicillamine was tethered to the FS particles by suspending $1 \mathrm{~g}$ of aminopropyl FS in a pyridine solution containing $1.2 \mathrm{~g}$ of the $\mathrm{N}$-acetyl-DLpenicillamine thiolactone and stirring at room temperature for $24 \mathrm{~h}$. Particles were washed three times with fresh $\mathrm{CHCl}_{3}$ and vacuum dried.

The free thiol groups of each type of derivatized FS were converted to their corresponding RSNO by reaction with $t$-butylnitrite. Before using the $t$-butylnitrite, this reagent was extracted over an aqueous solution containing the copper chelator cyclam $(15 \mathrm{mM})$ to remove copper ions added to stabilize the $t$-butylnitrite. NO-Cys-FS and SNAC-FS were then formed by suspending the corresponding thiol-derivatized FS in $10 \%$ methanol $/ 90 \%$ toluene $(\mathrm{v} / \mathrm{v})$ and adding $10 \%$ by volume $t$-butylnitrite. The reaction vessel was shielded from light and gently shaken for $1 \mathrm{~h}$ to form the RSNOs. SNAP-FS was formed by suspending the $\mathrm{N}$-acetylpenicillamine particles in toluene and adding $10 \%$ by volume of the extracted $t$-butylnitrite. The derivatized mixture was protected from light and shaken for $1 \mathrm{~h}$ to form the $S$-nitroso- $N$-acetylpenicillamine-derivatized particles. The particles were then washed three times with fresh toluene, vacuum dried, and stored in the dark at $4^{\circ} \mathrm{C}$.

\section{FQCA test for free primary amines}

A $100 \mu M$ solution of glycine was used as the standard amine solution for quantitative measurement of amine content on the FS particles. The amine standards and amine-containing FS samples were combined with $200 \mu \mathrm{L}$ of $5 \mathrm{mM}$ FCQA and brought to a total volume of $4 \mathrm{~mL}$ with a solution of $5 \mathrm{mM} \mathrm{KCN}$. Samples were protected from light and placed on a shaker at room temperature for $1 \mathrm{~h}$. Fluorescence measurements were made with an excitation wavelength of $480 \mathrm{~nm}$ and emission spectra were recorded from 500 to $800 \mathrm{~nm}$ using a Shimadzu RF-1501 spectrofluorophotometer (Tokyo, Japan).

\section{Ellman's test for free sulfhydryls}

Thiol standards were prepared using $1 \mathrm{mM}$ cysteine in $100 \mathrm{mM}$ phosphate buffer ( $\mathrm{pH} \mathrm{8.0)}$. One hundred microliters of $10 \mathrm{mM}$ Ellman's reagent and the thiol standards and/or samples were brought to a total volume of $4 \mathrm{~mL}$ by the addition of $100 \mathrm{mM}$ phosphate buffer ( $\mathrm{pH}$ 8.0). The samples were shaken for $1 \mathrm{~h}$ at room temperature and $200-\mu \mathrm{L}$ aliquots were pipetted into a 96-well microtiter plate. Absorbance values for each well were recorded with a Labsystems Multiskan $\mathrm{RC}$ microtiter plate reader using a 414-nm filter (Fisher Scientific).

\section{NO-release measurements}

NO generated from derivatized FS was measured using a Sievers Nitric Oxide Analyzer 280 (Boulder, $\mathrm{CO})$. NO was continuously swept from the headspace of the sample vessel and purged from the bathing solution with an $\mathrm{N}_{2}$ sweep gas and bubbler into the chemiluminescence detection chamber. Amber glass sample vessels were used for measurement of copper ion and ascorbate-initiated NO release from the particles or polymer films containing the filler particles. Clear glass sample vessels were used for photoinitiated NO-generation experiments.

\section{Trilayer polymer film preparation}

Teflon plates and 2.5-cm-diameter rings were machined in-house for use as casting molds for preparing polymer films containing the various nitrosothiol-derivatized FS particles. The cocktail used to cast plasticized PU films consisted of $0.6 \mathrm{~g}$ of Tecoflex PU and $1.2 \mathrm{~g}$ of NPOE dissolved in $10 \mathrm{~mL}$ of THF. The cocktail used to prepare the SR films contained $1.6 \mathrm{~g}$ of SR dissolved in $10 \mathrm{~mL}$ of toluene with vortex mixing. After mixing for several hours, $400 \mu \mathrm{L}$ of this cocktail was cast into the Teflon ring which was loosely covered and allowed to dry for $4 \mathrm{~h}$. The center layer was cast by pipetting $400 \mu \mathrm{L}$ of a solution of $30 \mathrm{mg}$ of derivatized FS in $1 \mathrm{~mL}$ of the given polymer cocktail on top of the first layer and allowed to dry for $4 \mathrm{~h}$, protected from light. The final layer (top) was cast by pipetting $400 \mu \mathrm{L}$ of the original polymer cocktail on top of the cured center layer. The composite films were allowed to cure overnight, completely protected from light. Smaller $0.7-\mathrm{cm}$-diameter disks were cut from the cured parent films and used to characterize NO release from the final layered polymer material, in the presence of $\mathrm{Cu}(\mathrm{II})$, ascorbate, and light. 
TABLE I

Characterization of S-Nitrosothiol-Derivatized Fumed Silica Particles

\begin{tabular}{cccccc}
\hline Particles & $\begin{array}{c}\text { Total Amine } \\
(\mathrm{mol} / \mathrm{mg})\end{array}$ & $\begin{array}{c}\text { Free Amine } \\
\text { After Coupling } \\
(\mathrm{mol} / \mathrm{mg})\end{array}$ & $\begin{array}{c}\text { Occupied Amine } \\
(\mathrm{mol} / \mathrm{mg})\end{array}$ & $\begin{array}{c}\text { Free Sulfhydryl } \\
(\mathrm{mol} / \mathrm{mg})\end{array}$ & $\begin{array}{c}\text { Total NO Loading } \\
(\mathrm{mol} / \mathrm{mg})\end{array}$ \\
\hline $\begin{array}{c}\text { Aminopropyl } \\
\text { fumed silica }\end{array}$ & $3.07 \times 10^{-7} \pm 0.21$ & & & & \\
NO-Cys-FS $^{\mathrm{a}}$ & $3.07 \times 10^{-7} \pm 0.21$ & $3.14 \times 10^{-7} \pm 0.15$ & $\mathrm{NA}$ & $0.24 \times 10^{-7} \pm 0.06$ & $0.21 \times 10^{-7} \pm 0.07$ \\
SNAC-FS $^{\mathrm{b}}$ & $3.07 \times 10^{-7} \pm 0.21$ & $2.06 \times 10^{-7} \pm 0.07$ & $1.01 \times 10^{-7}$ & $0.69 \times 10^{-7} \pm 0.06$ & $0.44 \times 10^{-7} \pm 0.01$ \\
SNAP-FS $^{c}$ & $3.07 \times 10^{-7} \pm 0.21$ & $0.98 \times 10^{-7} \pm 0.09$ & $2.09 \times 10^{-7}$ & $1.42 \times 10^{-7} \pm 0.07$ & $1.38 \times 10^{-7} \pm 0.29$
\end{tabular}

${ }^{a} S$-Nitrosocysteine fumed silica.

${ }^{\mathrm{b}} S$-Nitroso- $N$-acetylcysteine fumed silica.

${ }^{\mathrm{C}} \mathrm{S}$-Nitroso- $\mathrm{N}$-acetylpenicillamine fumed silica.

\section{RESULTS AND DISCUSSION}

\section{Characterization of derivatized particles}

Three different thiols (cysteine, $\mathrm{N}$-acetylcysteine, and $\mathrm{N}$-acetylpenicillamine) were tethered to the surface of the FS particles and subsequently converted into the corresponding RSNOs as described in the Experimental section. The derivatized particles were characterized with respect to primary amine content, sulfhydryl content, and total NO loading to assess each step of the entire derivatization process. The fluorogenic agent FQCA, developed by Beale et al., ${ }^{30}$ was used to determine the primary amine content on the surface of the particles during the synthesis procedures. The FQCA reagent does not fluoresce until it reacts with a primary amine, eliminating the need to remove any unreacted reagent before measuring the emission spectrum intensity. The total amount of free sulfhydryl groups on the surface of the particles was determined using Ellman's reagent, ${ }^{31,32}$ and the total NO loading of the derivatized particles was monitored via chemiluminescence using multiple injections of $250 \mu \mathrm{M}$ copper ions to initiate complete NO release.

Table I lists the amine content of the aminopropyl FSs, the amine content after coupling and deprotection of the thiol species to the FSs, the calculated amount of occupied amine, the resulting sulfhydryl content, and the total NO loading of the various particles after reaction with $t$-butylnitrite. In the case of Cys-FS, the total amine content should remain unchanged because for every one primary amine group used to form an amide bond with the amino acid, cysteine itself has one free primary amine. In the case of both $\mathrm{N}$-acetylcysteine and $N$-acetylpenicillamine coupling, the total amount of primary amine should decrease in a 1:1 ratio with the coupled thiol species. The amount of occupied amine sites was determined by subtracting the free amine content after coupling from the total amine content determined before the coupling reaction. The free sulfhydryl content should be equal to the amount of occupied amine sites and the total NO loading should also equal the free sulfhydryl content because, for each amine occupied, one thiol group has been tethered to the surface.

As indicated in Table I, the amount of total alkyl amine linked to the surface of the particles after silanization was $3.07 \pm 0.21 \times 10^{-7} \mathrm{~mol} / \mathrm{mg}$. After coupling cysteine to the FS and deprotecting the amino acid, $3.14 \pm 0.15 \times 10^{-7} \mathrm{~mol} / \mathrm{mg}$ of amine sites were detected. This is consistent with the expectation that the total measured amine content should not change because cysteine contains a primary amine group. The free sulfhydryl detected for the same particles was $0.24 \pm 0.06 \times 10^{-7} \mathrm{~mol} / \mathrm{mg}$ with $0.21 \pm$ $0.07 \times 10^{-7} \mathrm{~mol} / \mathrm{mg}$ total NO loading after reaction with butylnitrite. The SNAC-FS particles possessed $2.06 \pm 0.07 \times 10^{-7} \mathrm{~mol} / \mathrm{mg}$ free amine after coupling, indicating that $1.01 \times 10^{-7} \mathrm{~mol} / \mathrm{mg}$ of amine sites were reacted with the SNAC. The free sulfhydryl content was $0.69 \pm 0.06 \times 10^{-7} \mathrm{~mol} / \mathrm{mg}$ and after reaction with $t$-butylnitrite, the total NO loading was determined to be $0.30 \pm 0.24 \times 10^{-7} \mathrm{~mol} / \mathrm{mg}$ total NO loading. The somewhat low level of NO loading in the case of SNAC-FS could be a result of the instability of primary and secondary RSNOs. ${ }^{22}$ The amount of free amine present after coupling $\mathrm{N}$-acetyl-DL-penicillamine was $0.98 \pm 0.09 \times 10^{-7} \mathrm{~mol} / \mathrm{mg}$, indicating that $2.07 \times 10^{-7} \mathrm{~mol} / \mathrm{mg}$ of initial amine sites were occupied. The free sulfhydryl measured was $1.42 \pm 0.07 \times$ $10^{-7} \mathrm{~mol} / \mathrm{mg}$ and the total NO loading was $1.38 \pm$ $0.29 \times 10^{-7} \mathrm{~mol} / \mathrm{mg}$. For the SNAP-FS particles, these values are highest among the data for all three thiol species tethered to the FS particles. Indeed, SNAP-FS had twice the sulfhydryl content of SNAC-FS and nearly six times the sulfhydryl content of NO-Cys-FS. This could be attributed to the fact that the self-protected thiolactone (used in the SNAP-FS synthesis) is much smaller in size than the uronium salt complex formed with HBTU, the reagent used to couple protected cysteine and acetylcysteine molecules to the surface of the particles. Hence, steric hindrance for the surface reaction would be much less in the case of the SNAP-FS system 
A.

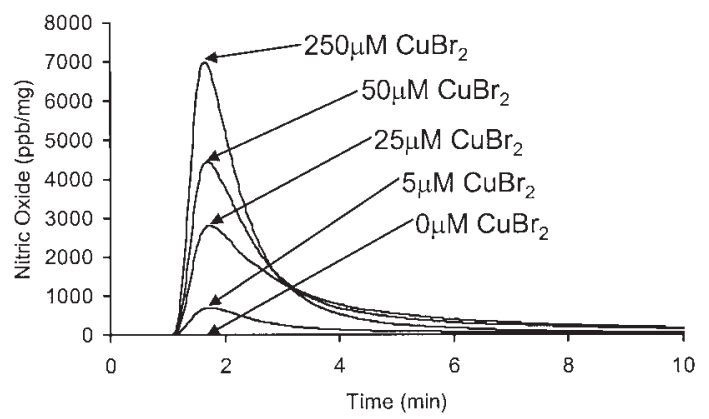

B.

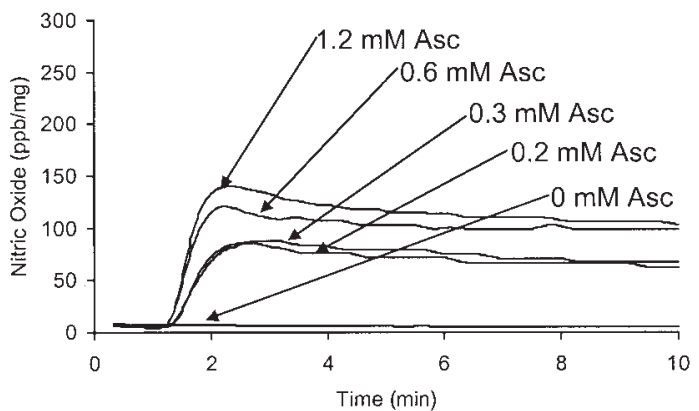

C.

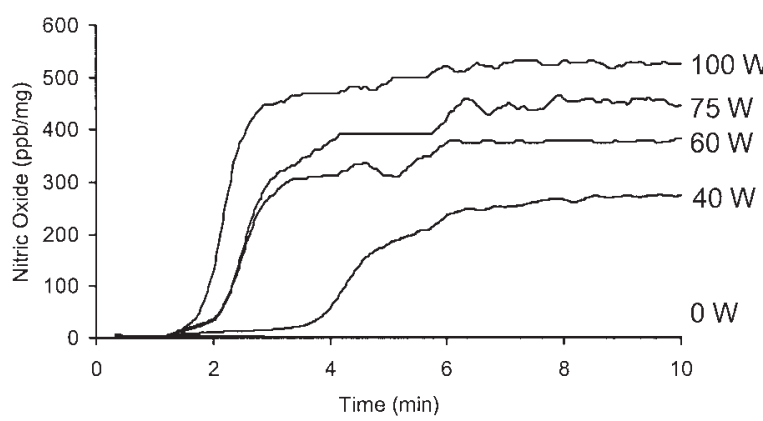

Figure 2. NO generation monitored via chemiluminescence from SNAP-FS suspended in toluene upon (A) the addition of copper ions, (B) the addition of ascorbate, and (C) exposure to light.

\section{NO release from free RSNO-derivatized FS}

NO release from these three types of derivatized particles was monitored via chemiluminescence. Three dif- ferent initiators were used to generate NO from the derivatized particles: a) copper(II) ions, b) ascorbate, and c) light. Particles were suspended in $2 \mathrm{~mL}$ of toluene and each sample was analyzed in triplicate.

Figure 2 shows representative NO-release curves for SNAP-FS upon addition of copper(II) bromide, sodium ascorbate, and exposure to increasing power of light. Tables II-IV list the amount of NO generated by NO-Cys-FS, SNAC-FS, and SNAP-FS, respectively, using the same initiators and the percentage of total NO that was released in the first 10-min period.

Although copper(I) is the active species that produces NO from RSNOs, the addition of copper(II) initiated NO release from all of the derivatized particles. There are likely trace levels of free thiols present on the surface of the particles even after the reaction with $t$-butylnitrite. Thiolate ions are sufficient reducing agents to generate copper(I) from copper(II). ${ }^{22}$ All three derivatized particles exhibited increased $\mathrm{NO}$ generation with increasing levels of copper(II). All three particle types also showed increased NO generation with increasing ascorbate concentrations. This is interesting because ascorbate is reported to only reduce RSNOs directly to NO at greater than millimolar levels. ${ }^{23}$ However, even when the ascorbate concentration was only $0.2,0.3$, and $0.6 \mathrm{mM}$, decomposition and $\mathrm{NO}$ generation from the particles was observed for NO-Cys-FS, SNAC-FS, and SNAP-FS. The derivatized particles as suspensions in the toluene solution also released increasing amounts of $\mathrm{NO}$ when exposed to increasing power of light $(0-100 \mathrm{~W})$.

Figure 3 shows that the photoinitiated NO-release phenomenon is controllable. SNAP-FS suspended in toluene was exposed to light of two different intensities for $\sim 20$-s periods and then returned to a dark state. NO generation initiated and ceased as the light was turned on and off. This provides a potentially powerful external on/off trigger to generate $\mathrm{NO}$ for defined durations and fluxes as needed for various

TABLE II

Nitric Oxide (NO) Released from S-Nitrosocysteine-Derivatized Fumed Silica (NO-Cys-FS) Particles Suspended in Toluene

\begin{tabular}{|c|c|c|c|c|c|c|c|c|}
\hline \multicolumn{3}{|c|}{ Copper Initiator } & \multicolumn{3}{|c|}{ Ascorbate Initiator } & \multicolumn{3}{|c|}{ Photoinitiation } \\
\hline$\mu M \mathrm{CuBr}_{2}{ }^{\mathrm{a}}$ & $\begin{array}{l}\text { nmol NO } \\
\text { Released }^{\mathrm{b}}\end{array}$ & $\begin{array}{l}\% \text { of Total NO } \\
\text { Released }^{c}\end{array}$ & $\begin{array}{c}\mathrm{mM} \\
\text { Ascorbate }^{\mathrm{a}}\end{array}$ & $\begin{array}{l}\text { nmol NO } \\
\text { Released }^{\mathrm{b}}\end{array}$ & $\begin{array}{c}\% \text { of Total NO } \\
\text { Released }^{\mathrm{c}}\end{array}$ & $\begin{array}{l}\text { Wattage of } \\
\text { Light }^{\mathrm{d}}\end{array}$ & $\begin{array}{l}\text { nmol NO } \\
\text { Released }^{\mathrm{b}}\end{array}$ & $\begin{array}{l}\% \text { of Total NO } \\
\text { Released }^{c}\end{array}$ \\
\hline 0 & $1.13 \pm 0.31$ & 5.36 & 0 & $1.13 \pm 0.31$ & 5.36 & 0 & $0.27 \pm 0.11$ & 1.30 \\
\hline 5 & $1.94 \pm 0.15$ & 9.24 & 0.2 & $2.58 \pm 0.12$ & 12.3 & 40 & $0.64 \pm 0.03$ & 3.04 \\
\hline 25 & $2.54 \pm 0.19$ & 12.1 & 0.3 & $2.23 \pm 0.04$ & 10.6 & 60 & $0.78 \pm 0.09$ & 3.70 \\
\hline 50 & $3.69 \pm 0.50$ & 17.6 & 0.6 & $2.20 \pm 0.06$ & 10.5 & 75 & $1.03 \pm 0.31$ & 4.91 \\
\hline 250 & $8.42 \pm 0.82$ & 40.1 & 1.2 & $3.18 \pm 0.04$ & 15.1 & 100 & $0.93 \pm 0.17$ & 4.41 \\
\hline
\end{tabular}

${ }^{a}$ Final concentration of initiator added after $2 \mathrm{~min}$.

${ }^{\text {b }} \mathrm{NO}$ released after first $10 \mathrm{~min}$.

${ }^{\mathrm{C} C a l c u l a t e d}$ based on total NO loading reported in Table I.

${ }^{\mathrm{d}}$ Philips Director bulbs used to illuminate reaction cell. 
TABLE III

Nitric Oxide (NO) Released from $S$-Nitroso- $N$-acetylcysteine-Derivatized Fumed Silica (SNAC-FS) Particles Suspended in Toluene

\begin{tabular}{|c|c|c|c|c|c|c|c|c|}
\hline \multicolumn{3}{|c|}{ Copper Initiator } & \multicolumn{3}{|c|}{ Ascorbate Initiator } & \multicolumn{3}{|c|}{ Photoinitiation } \\
\hline$M M C_{11 B r}{ }^{a}$ & nmol NO & $\%$ of Total NO & $\mathrm{m} M$ & nmol NO & $\%$ of Total NO & Wattage of & nmol NO & $\%$ of Total NO \\
\hline & & & & & & & & \\
\hline 0 & $0.44 \pm 0.32$ & 0.99 & 0 & $0.44 \pm 0.32$ & 0.99 & 0 & $0.17 \pm 0.03$ & 0.38 \\
\hline 5 & $6.99 \pm 0.65$ & 15.9 & 0.2 & $3.97 \pm 0.74$ & 9.02 & 40 & $2.04 \pm 0.22$ & 4.64 \\
\hline 25 & $9.93 \pm 0.79$ & 22.6 & 0.3 & $4.82 \pm 0.39$ & 11.0 & 60 & $3.17 \pm 0.20$ & 7.21 \\
\hline 50 & $10.81 \pm 1.34$ & 24.6 & 0.6 & $6.52 \pm 0.57$ & 14.8 & 75 & $3.30 \pm 0.22$ & 7.50 \\
\hline 250 & $31.91 \pm 1.28$ & 72.5 & 1.2 & $10.07 \pm 0.06$ & 22.9 & 100 & $4.19 \pm 0.59$ & 9.53 \\
\hline
\end{tabular}

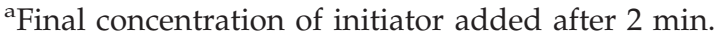

${ }^{\mathrm{b}} \mathrm{NO}$ released after first $10 \mathrm{~min}$.

${ }^{\mathrm{C}}$ Calculated based on total NO loading reported in Table I.

dPhilips Director bulbs used to illuminate reaction cell.

biomedical applications, and/or fundamental studies regarding the effect of given NO doses on living cells, etc.

\section{NO release from RSNO-derivatized FS embedded in trilayer polymer films}

To create more biocompatible coatings, or to use the RSNO-derivatized FS particles for creating surfaces with controlled NO fluxes for fundamental studies, it will be necessary to incorporate these new materials into appropriate polymeric films. To establish the feasibility of creating such films, the SNAC-FS and SNAP-FS particles were blended into the middle layer of plasticized PU or SR films (note: because of the low NO loading and instability of NO-Cys-FS, these particles were not used in such studies).

Trilayer PU/NPOE films [see Fig. 4(A) for schematic of film configuration] were cast containing $20 \mathrm{wt}$ $\%$ SNAC-FS in the center layer. The cured films were cut into small disks and immersed in phosphate-buffered saline (PBS) ( $\mathrm{pH}$ 7.4) that was first washed over Chelex resin to remove residual copper ions from the buffer. Injections of copper ions and/or ascorbate were made to initiate NO release. Unlike the free particles, NO was not generated from SNAC-FS in PU when only copper ions or only ascorbate was added to the bathing solution. When the same films were immersed in PBS that contained $5 \mathrm{mM}$ ascorbate, NO was generated upon the addition of copper ions. This indicates that an external reducing agent is required to generate enough $\mathrm{Cu}^{+1}$ to diffuse into the PU polymer and release NO from the particles that are embedded within the PU/NPOE matrix. As increased concentrations of copper were added $(0-250 \mu M)$, the surface flux of NO increased from $\sim 0.1$ to $0.7 \times 10^{-10} \mathrm{~mol}$ $\mathrm{cm}^{-2} \mathrm{~min}^{-1}$. The NO generation from a polymer film containing SNAC-FS from the same parent film exposed to 100-W light generated a NO flux of only $\sim 0.3 \times 10^{-10} \mathrm{~mol} \mathrm{~cm}^{-2} \mathrm{~min}^{-1}$. This low efficiency of photoinitiated NO release could be because the plasticizer used (NPOE) within the film attenuates the visible light that initiates NO release from the RSNO. Additionally, THF was used as the casting solvent for the PU films and it has been observed to decompose free SNAC and SNAP in solution (unpublished data). Thus, there is probably a significant loss of the RSNO

TABLE IV

Nitric Oxide (NO) Released from $S$-Nitroso- $\mathrm{N}$-acetylpenicillamine-Derivatized Fumed Silica (SNAP-FS) Particles Suspended in Toluene

\begin{tabular}{|c|c|c|c|c|c|c|c|c|}
\hline \multicolumn{3}{|c|}{ Copper Initiator } & \multicolumn{3}{|c|}{ Ascorbate Initiator } & \multicolumn{3}{|c|}{ Photoinitiation } \\
\hline$\mu M \mathrm{CuBr}_{2}{ }^{\mathrm{a}}$ & $\begin{array}{l}\text { nmol NO } \\
\text { Released }^{\mathrm{b}}\end{array}$ & $\begin{array}{l}\% \text { of Total NO } \\
\text { Released }^{c}\end{array}$ & $\begin{array}{c}\mathrm{m} M \\
\text { Ascorbate }^{\mathrm{a}}\end{array}$ & $\begin{array}{l}\text { nmol NO } \\
\text { Released }^{\mathrm{b}}\end{array}$ & $\begin{array}{l}\% \text { of Total NO } \\
\text { Released }^{c}\end{array}$ & $\begin{array}{l}\text { Wattage of } \\
\text { Light }^{\mathrm{d}}\end{array}$ & $\begin{array}{l}\text { nmol NO } \\
\text { Released }^{\mathrm{b}}\end{array}$ & $\begin{array}{l}\% \text { of Total NO } \\
\text { Released }^{c}\end{array}$ \\
\hline 0 & $0.00 \pm 0.01$ & 0.00 & 0 & $0.38 \pm 0.02$ & 0.28 & 0 & $0.19 \pm 0.022$ & 0.14 \\
\hline 5 & $9.99 \pm 1.04$ & 7.24 & 0.2 & $4.17 \pm 0.03$ & 3.02 & 40 & $9.54 \pm 1.44$ & 6.91 \\
\hline 25 & $44.16 \pm 3.98$ & 32.0 & 0.3 & $4.07 \pm 0.04$ & 2.95 & 60 & $16.13 \pm 1.88$ & 11.7 \\
\hline 50 & $52.76 \pm 3.76$ & 38.2 & 0.6 & $5.55 \pm 0.03$ & 4.02 & 75 & $17.31 \pm 1.81$ & 12.5 \\
\hline 250 & $54.67 \pm 2.62$ & 39.6 & 1.2 & $6.44 \pm 0.03$ & 4.67 & 100 & $23.07 \pm 4.20$ & 16.7 \\
\hline
\end{tabular}

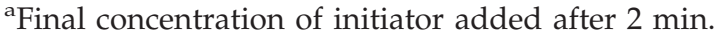

bNO released after first $10 \mathrm{~min}$.

${ }^{\mathrm{C} C a l c u l a t e d}$ based on total NO loading reported in Table I.

${ }^{\mathrm{d}}$ Philips Director bulbs used to illuminate reaction cell. 


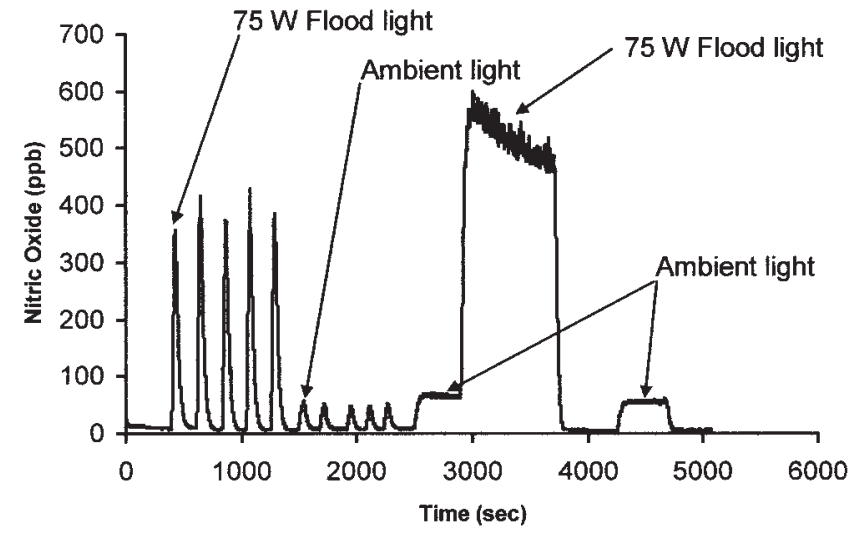

Figure 3. NO generation monitored via chemiluminescence from SNAP-derivatized FS suspended in toluene exposed to alternating periods of light and dark, demonstrating the on/off capability of NO generation from the derivatized particles.

during the casting procedure, resulting in a much smaller reservoir of $\mathrm{NO}$ donor present to generate $\mathrm{NO}$ in the cured films. Because there was a fairly low

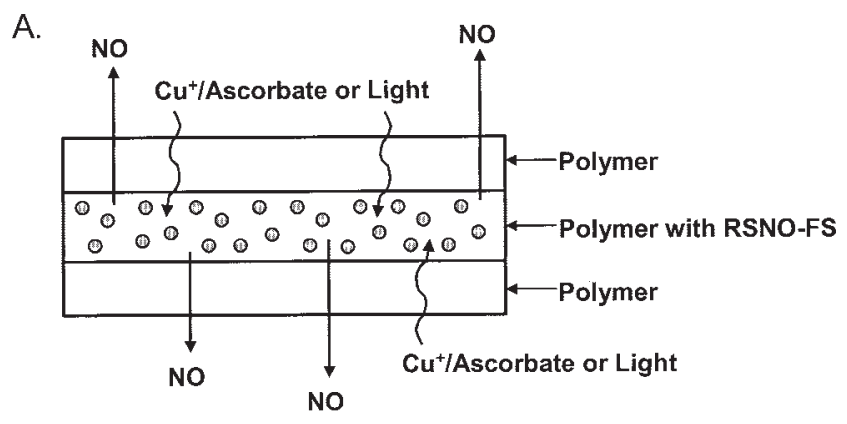

B.

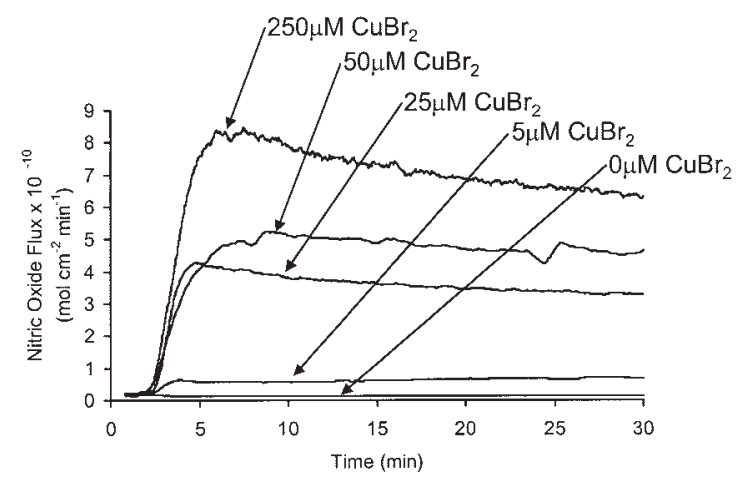

Figure 4. (A) Schematic diagram of trilayer polymer films containing RSNO-derivatized FS particles blended into the center layer and (B) NO flux generated from $0.7-\mathrm{cm}$-diameter disks of plasticized PU with $20 \mathrm{wt} \%$ SNAP-FS blended into the center layer (film composed of $33 \mathrm{wt} \%$ SG-80A PU/67 wt \% NPOE, total thickness $\sim 100 \mu \mathrm{m})$. The disks were submerged in PBS containing $5 \mathrm{mM}$ ascorbate with added copper ions. NO was measured via chemiluminescence.

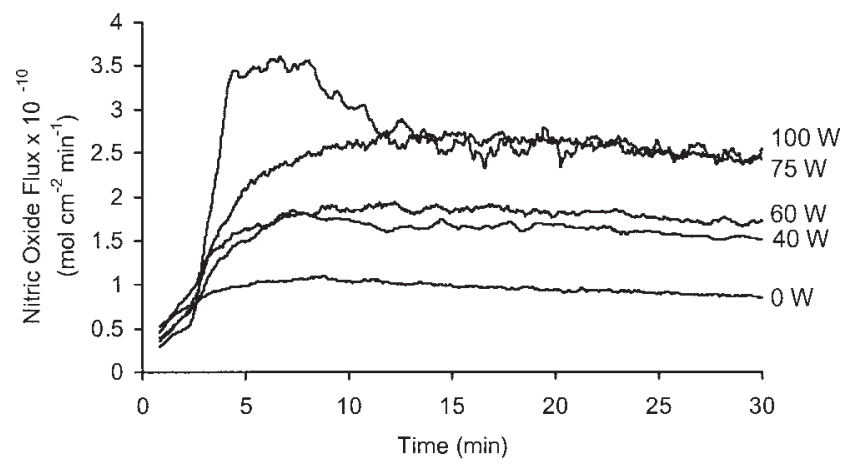

Figure 5. NO flux generated from $0.7-\mathrm{cm}$-diameter disks of SR film with 20 wt \% SNAC-FS blended into the center layer (film composed of RTV 3140 SR, total thickness $\sim 100$ $\mu \mathrm{m})$. Disks were submerged in PBS and exposed to increasing power of light while NO was monitored via chemiluminescence.

generation of NO from films with SNAC-FS in PU/ NPOE, no further studies were conducted with this system.

Trilayer PU/NPOE films containing $20 \mathrm{wt} \%$ SNAP-FS in the center layer were cast and tested for NO-release properties. Figure 4(B) shows NO generation from $0.7-\mathrm{cm}$-diameter disks of SNAP-FS in cured PU/NPOE films immersed in $2 \mathrm{~mL}$ of Chelex washed PBS. NO is not generated when copper ions $(250 \mu M$ final concentration) or ascorbate ( $5 \mathrm{mM}$ final concentration) alone are added (data not shown). If $250 \mu M$ copper ions and $5 \mathrm{mM}$ ascorbate are added simultaneously, a significant flux of $\mathrm{NO}$ is observed $(\sim 7.5 \times$ $\left.10^{-10} \mathrm{~mol} \mathrm{~cm}^{-2} \mathrm{~min}^{-1}\right)$. This film was also soaked in fresh rabbit plasma to determine if endogenous reducing equivalents in blood could cause significant $\mathrm{NO}$ generation from these films. It was found that $\mathrm{NO}$ is not generated when the films are soaked in the plasma (data not shown). This is potentially very useful because it implies that NO will not be spontaneously released from this material in a fresh blood environment. Figure 4(B) shows the increased NO generation from the SNAP-FS in PU/NPOE films when $5 \mathrm{mM}$ ascorbate is present in the buffer and the copper ion concentration is increased from 0 to $250 \mu \mathrm{M}$. It is clear that a NO flux greater than that generated by the endothelial cell layer (estimated 1-4 $\times 10^{-10} \mathrm{~mol} \mathrm{~cm}^{-2}$ $\left.\min ^{-1}\right)^{33}$ can be achieved with such a film when both ascorbate and copper(II) are present.

Trilayer SR films were also cast with 20 wt \% SNAC-FS or $20 \mathrm{wt} \%$ SNAP-FS blended into the center layer. Copper ions (250 $\mu M$ final concentration) and copper ions with ascorbate (5 $\mathrm{mM}$ final concentration) injected into the PBS solution containing a small disk of the SNAC-FS in SR yielded very low NO fluxes roughly equal to or less than the level of NO generated in a control film with no added copper or reducing agent (data not shown). This result is not surprising. 


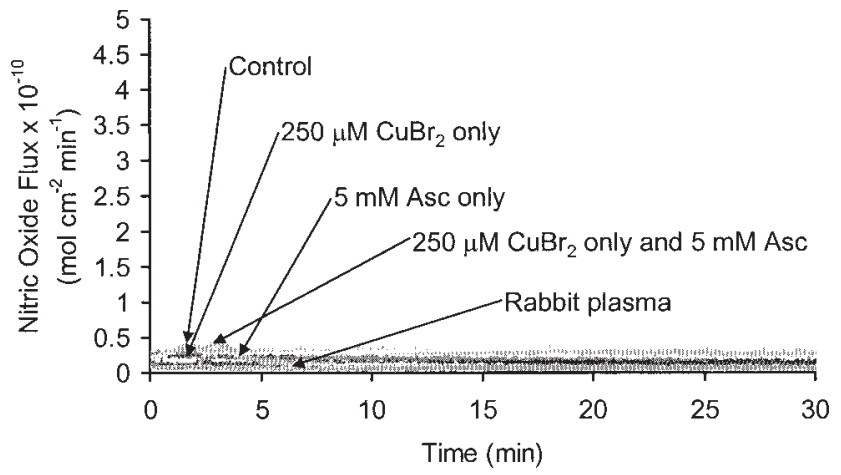

Figure 6. NO flux generated from 0.7-cm-diameter disks of SR film with 20 wt \% SNAP-FS blended into the center layer (film composed of RTV 3140 SR, total thickness $\sim 100$ $\mu \mathrm{m})$. Disks were submerged in PBS with added copper ions and/or ascorbate or soaked in fresh rabbit plasma. NO generation was monitored via chemiluminescence.

Indeed, given the very hydrophobic nature of SR, copper ions and ascorbate do not permeate into such films to react with the embedded RSNO species. Figure 5 shows the NO generation from pieces of the same SNAC-FS SR parent film exposed to increasing intensities of visible light. As the power of light is increased (darkness, 40-, 60-, 75-, and 100-W light), the flux of NO increases. Physiologically relevant NO fluxes ranging from 0.9 to $\sim 3.0 \times 10^{-10} \mathrm{~mol} \mathrm{~cm}^{-2}$ $\min ^{-1}$ were obtained.

Trilayer SR films were also cast with $20 \mathrm{wt} \%$ SNAP-FS blended into the center layer. Figure 6 shows the NO generated from small disks of the parent film in PBS with added copper ions $(250 \mu M$ final concentration) and/or ascorbate (5 $\mathrm{mM}$ final concentration), or soaked in fresh rabbit plasma. Essentially no NO is generated in any of these solutions, indicating once again (as above) that the SR is an effective barrier for protecting the embedded SNAP-FS particles from copper(II)-induced decomposition as well as

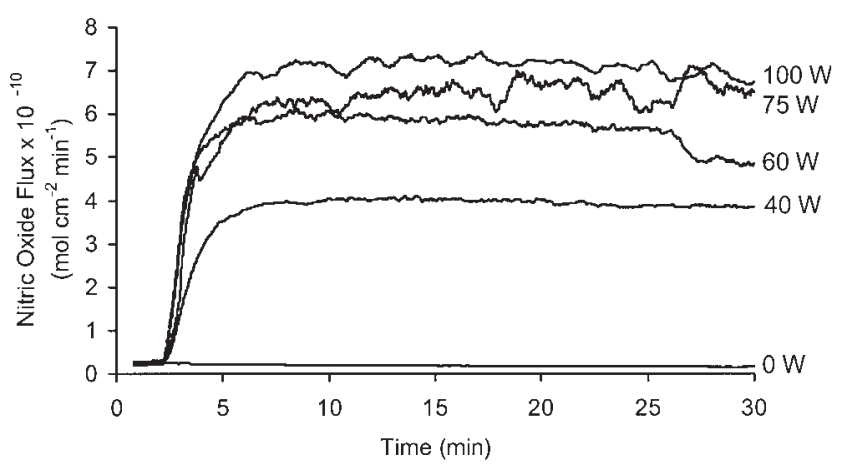

Figure 7. NO flux generated from 0.7-cm-diameter disks of SR film with $20 \mathrm{wt} \%$ SNAP-FS blended into the center layer (film composed of RTV 3140 SR, total thickness $\sim 100$ $\mu \mathrm{m})$. Disks were submerged in PBS and exposed to increasing power of light while NO generation was monitored via chemiluminescence.

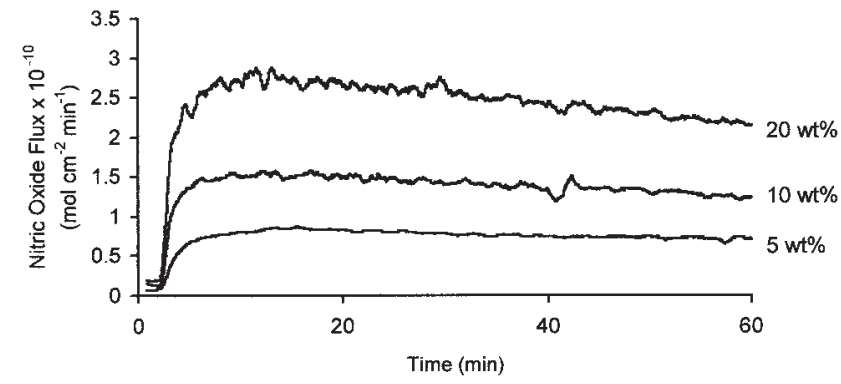

Figure 8. NO flux generated from 0.7-cm-diameter disks of SR film with 5, 10, and $20 \mathrm{wt} \%$ SNAP-FS blended into the center layer (film composed of RTV 3140 SR, total thickness $\sim 100 \mu \mathrm{m}$ ). Disks were submerged in PBS exposed to $40 \mathrm{~W}$ of light while NO was monitored via chemiluminescence.

preventing endogenous reducing agents present in plasma from generating NO. Figure 7 illustrates the level of NO generated from these same films soaked in PBS (pH 7.4) when exposed to visible light of increasing power. When the film is protected from light, there is no observable NO generation. As pieces of trilayer film are exposed to increasing light intensities, greater photoinitiated NO generation is observed. The steady state fluxes of $\mathrm{NO}$ obtained range from 0 to $\sim 7.0 \times$ $10^{-10} \mathrm{~mol} \mathrm{~cm}^{-2} \mathrm{~min}^{-1}$ depending on the power or radiation striking the film. As illustrated in Figure 8, different amounts of SNAP-FS blended into the SR films (5-20 wt \%) exhibit different steady-state levels of NO release. This indicates that the level of NO generated can be further controlled by changing the amount of $\mathrm{NO}$ donor blended into the multilayer polymer structure. In previous fundamental studies, it was shown that absorption of radiation at $590 \mathrm{~nm}$ is primarily responsible for the photoinitiated decomposition of the SNAP species and generation of NO from the polymeric films. ${ }^{28}$

Figure 9 shows the NO generated from SNAP-FS

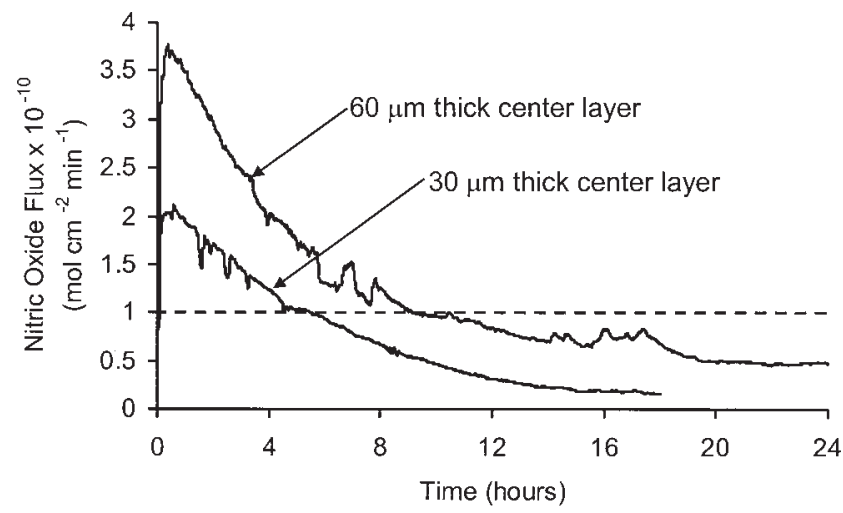

Figure 9. Long-term NO flux generated from 0.7-cm-diameter disks of SR film containing $20 \mathrm{wt} \%$ SNAP-FS in the center layer that was either $30-$ or $60-\mu \mathrm{m}$ thick. Films were submerged in PBS buffer (pH 7.4) and exposed to $40 \mathrm{~W}$ of light while NO generation was monitored via chemiluminescence. 
blended into the center layer of trilayer SR films in which the concentration of SNAP-FS is $20 \mathrm{wt} \%$, but this center layer is twice the thickness $(\sim 30$ and $\sim 60$ $\mu \mathrm{m})$. These films were exposed to $40 \mathrm{~W}$. The flux of NO release from the thicker films is nearly twofold that for the thinner film. The film prepared with the 60 - $\mu$ m-thick center layer releases NO above $\sim 1 \times$ $10^{-10} \mathrm{~mol} \mathrm{~cm}^{-2} \mathrm{~min}^{-1}$ level for nearly $12 \mathrm{~h}$ whereas the $30-\mu \mathrm{m}$-thick center layer releases $\mathrm{NO}$ at this level for approximately $5 \mathrm{~h}$. Clearly, however, increasing the thickness of the SNAP-FS layer provides an alternate means to control the NO-release characteristics of the multilayer films.

\section{CONCLUSIONS}

Results presented here show that cysteine, $N$-acetylcysteine, and $N$-acetylpenicillamine can all be tethered to the surface of FS particles and converted into corresponding nitrosothiols via reaction with $t$-butylnitrite. SNAP-FS had the greatest NO loading of the three types of particles synthesized. NO-Cys-FS, SNAC-FS, and SNAP-FS particles suspended in toluene all release increasing levels of NO upon addition of increasing levels of copper(II), ascorbate, or visible light. Polymeric films prepared by embedding the various derivatized particles into the center layer of trilayer configurations can liberate $\mathrm{NO}$ in response to either the presence of $\mathrm{Cu}(\mathrm{II})$, ascorbate, or light. However, the nature of the polymeric material dictates the level of NO flux that can be generated from such films in the presence of different NO-release initiators. SNAP-FS or SNAC-FS in an SR matrix only releases $\mathrm{NO}$ in the presence of visible light, whereas these same two particles in a PU matrix can release NO with either light, or a combination of copper(II) ions and a small amount of reducing agent (e.g., ascorbate).

It was further shown that the fluxes of NO from the various polymeric films can be controlled by a number of parameters, including the amount of derivatized FS particles embedded within the polymeric film, the thickness of the layer containing the particles, and the levels of $\mathrm{Cu}$ (II) ions/ascorbate bathing the film or the light intensity impinging on the layered polymer coating. These different control points offer the ability to create NO-releasing materials for specific applications. Additionally, other thiol groups or small chains of sulfur-containing amino acids could be tethered to the surface of the FS particles, offering the potential for different $\mathrm{NO}$ release profiles and greatly increased NO loading on the particles. It is envisioned that such RSNO-derivatized FS particles could be blended into many different polymers to impart NO-release properties that would improve the biocompatibility and ultimately the functionality of many biomedical devices fabricated from or coated with such materials.

M. C. Frost was supported by a fellowship from the NIH Cellular Biotechnology Training Program at the University of Michigan and a 2003 ACS Summer Fellowship from the Division of Analytical Chemistry.

\section{References}

1. Wise DL, Trantolo DJ, Lewandrowski K, Gresser JD, Cattaneo MV, Yaszemski, MJ, editors. Biomaterials engineering and devices: Human applications. Vol 1. Totowa, NJ: Humana Press; 2000.

2. Peppas NA, Langer R. New challenges in biomaterials. Science 1994;263:1715-1719.

3. Braybrook JH, editor. Biocompatibility assessment of medical devices and materials. New York: John Wiley \& Sons; 1997.

4. Mellion BT, Ignarro LJ, Ohlstein EH, Pontecorvo EG, Hyman $\mathrm{AL}$, Kadowitz PH. Evidence for the inhibitory role of guanosine $3^{\prime}, 5^{\prime}$-monophosphate in ADP-induced humanplatelet aggregation in the presence of nitric-oxide and related vasodilators. Blood 1981;57:946-955.

5. Radomski MW, Palmer MJ, Moncada S. The anti-aggregating properties of vascular endothelium: Interactions between prostacyclin and nitric oxide. Br J Pharmacol 1987;92:639-646.

6. Baek SH, Hrabie JA, Keefer LK, Hou DM, Fineberg N, Rhoades R, March KL. Augmentation of intrapericardial nitric oxide level by a prolonged-release nitric oxide donor reduces luminal narrowing after porcine coronary angioplasty. Circulation 2002;105:2779-2784.

7. Chaux A, Ruan XM, Fishbein MC, Ouyang Y, Kaul S, Pass JA, Matloff JM. Perivascular delivery of a nitric oxide donor inhibits neointimal hyperplasia in vein grafts implanted in the arterial circulation. J Thorac Cardiovasc Surg 1998;115:604-614.

8. Nablo BJ, Chen TY, Schoenfisch MH. Sol-gel derived nitric oxide releasing materials that reduce bacterial adhesion. J Am Chem Soc 2001;123:9712-9713.

9. MacMicking JL, Xie QW, Nathan C. Nitric oxide and macrophage function. Annu Rev Immunol 1997;15:323-350.

10. Batchelor MM, Reoma SL, Fleser PS, Nuthakki VK, Callahan RE, Shanley CJ, Politis JK, Elmore J, Merz SI, Meyerhoff ME. More lipophilic dialkyldiamine-based diazeniumdiolates: Synthesis, characterization, and application in preparing thromboresistant nitric oxide release polymeric coatings. J Med Chem 2003;46:5153-5161.

11. Kaul S, Cercek B, Rengstrom J, Xu XP, Molloy MD, Dimayuga P, Parikh AK, Fishbein MC, Nilsson J, Rajavashisth TB, Shah PK. Polymeric-based perivascular delivery of a nitric oxide donor inhibits intimal thickening after balloon denudation arterial injury: Role of nuclear factor-kappaB. J Am Coll Cardiol 2000;35:493-501.

12. Mowery KA, Schoenfisch MH, Saavedra JE, Keefer LK, Meyerhoff ME. Preparation and characterization of hydrophobic polymeric films that are thromboresistant via nitric oxide release. Biomaterials 2000;21:9-21.

13. Tierney TS, Clatterbuck RE, Lawson C, Thai Q, Rhines LD, Tamargo RJ. Prevention and reversal of experimental posthemorrhagic vasospasm by the periadventitial administration of nitric oxide from a controlled release polymer. Neurosurgery 2001;49:945-953.

14. Shishido SM, de Oliveira MG. Polyethylene glycol matrix reduces the rates of photochemical and thermal release of nitric oxide from $S$-nitroso- $N$-acetylcysteine. Photochem Photobiol 2000;71:273-280. 
15. Smith DJ, Chakravarthy D, Pulfer S, Simmons ML, Hrabie JA, Citro ML, Saavedra JE, Davies KM, Hutsell TC, Mooradian DL, Hanson SR, Keefer LK. Nitric oxide-releasing polymers containing the $[\mathrm{N}(\mathrm{O}) \mathrm{NO}](-)$ group. J Med Chem 1996;39:1148-1156.

16. Zhang HP, Annich GM, Miskulin J, Osterholzer K, Merz SI, Bartlett RH, Meyerhoff ME. Nitric oxide releasing silicone rubbers with improved blood compatibility: Preparation, characterization, and in vivo evaluation. Biomaterials 2002;23:1485-1494.

17. Bohl KS, West JL. Nitric oxide-generating polymers reduce platelet adhesion and smooth muscle cell proliferation. Biomaterials 2000;21:2273-2278.

18. Zhang H, Annich GM, Miskulin J, Stankiewicz K, Osterholzer K, Merz SI, Bartlett RH, Meyerhoff ME. Nitric oxide-releasing fumed silica particles: Synthesis, characterization, and biomedical application. J Am Chem Soc 2003;125:5015-5024.

19. Jourd'heuil D, Hallén K, Feelish M, Grisham MB. Dynamic state of $S$-nitrosothiols in human plasma and whole blood. Free Radic Biol Med 2000;28:409-417.

20. Tyurin VA, Tyurina YY, Liu SX, Bayir H, Hubel CA, Kagan VE. Quantitation of $S$-nitrosothiols in cells and biological fluids. Methods Enzymol 2002;352:347-369.

21. Williams DLH. The chemistry of $S$-nitrosothiols. Acc Chem Res 1999;32:869-876.

22. Dicks AP, Swift HR, Williams DLH, Butler AR, Al-Sadoni HH, Cox BGJ. Identification of $\mathrm{Cu}^{+}$as the effective reagent in nitric oxide formation from S-nitrosothiols (RSNO). J Chem Soc Perkin Trans 2 1996:481-487.

23. Holmes AJ, Williams DLHJ. Reaction of ascorbic acid with $S$-nitrosothiols: Clear evidence for two distinct reaction pathways. J Chem Soc Perkin Trans 2 2000:1639-1644.

24. Singh RJ, Hogg N, Joseph J, Kalyanaraman B. Mechanism of nitric oxide release from S-nitrosothiols. J Biol Chem 1996;271: 18596-18603.
25. Andrews KL, McGuire JJ, Triggle CR. A photosensitive vascular smooth muscle store of nitric oxide in mouse aorta: No dependence on expression of endothelial nitric oxide synthase. Br J Pharmocol 2003;138:932-940.

26. Etchenique R, Furman M, Olabe JA. Photodelivery of nitric oxide from a nitrosothiol-derivatized surface. J Am Chem Soc 2000;122:3967-3968.

27. Shishido SM, Seabra AB, Loh W, de Oliveira MG. Thermal and photochemical nitric oxide release from $S$-nitrosothiols incorporated into Pluronic F127 gel: Potential uses for local and controlled nitric oxide release. Biomaterials 2003;24: 3543-3553.

28. Frost MC, Meyerhoff ME. Controlled photoinitiated release of nitric oxide from polymer films containing $S$-nitroso- $N$-acetylDL-penicillamine derivatized fumed silica filler. J Am Chem Soc 2004;126:1348-1349.

29. Zee-Cheng KY, Cheng CC. Experimental antileukemic agents. Preparation and structure-activity study of S-tritylcysteine and related compounds. J Med Chem 1970;13:414-418.

30. Beale SC, Hsieh YZ, Wiesler D, Novotny M. Application of 3-(2-furoyl)quinoline-2-carbaldehyde as a fluorogenic reagent for the analysis of primary amines by liquid chromatography with laser-induced fluorescence detection. J Chromatogr A 1990;499:579-587.

31. Ellman GL. Tissue sulfhydryl groups. Arch Biochem Biophys 1959;82:70-77.

32. Riddles PW, Blakeley RL, Zerner B. Ellman's reagent-5,5'dithiobis(2-nitrobenzoic acid)—re-examined. Anal Biochem 1979;94:75-81.

33. Vaughn MW, Kuo L, Liao JC. Estimation of nitric oxide production and reaction rates in tissue by use of a mathematical model. Am J Physiol 1998;274:H2163-H2176. 